\title{
Correction to: Effects of multi-component mixtures from sewage treatment plant effluent on common carp (Cyprinus carpio) under fully realistic condition
}

\section{Pham Thai Giang $\mathbb{D}^{1} \cdot$ Viktoriia Burkina $^{1} \cdot$ Sidika Sakalli $^{1} \cdot$ Heike Schmidt-Posthaus ${ }^{2} \cdot$ Martin Krøyer Rasmussen $^{3}$. Tomas Randak $^{1} \cdot$ Roman Grabic $^{1} \cdot K_{\text {Katerina Grabicova }}{ }^{1}$ Ganna Fedorova ${ }^{1} \cdot$ Olga Koba $^{1} \cdot$ Oksana Golovko $^{1}$. Jan Turek ${ }^{1} \cdot$ Daniel Cerveny $^{1} \cdot$ Jitka Kolarova $^{1} \cdot$ Vladimir Zlabek $^{1}$}

Published online: 5 February 2018

(c) Springer Science+Business Media, LLC, part of Springer Nature 2018

\section{Correction to: Environmental Management}

$$
\text { https://doi.org/10.1007/s00267-017-0964-7 }
$$

The original version of this Article unfortunately contained an error. The authors' given and family names were transposed erroneously. It has been corrected now in this Erratum.

The original article has also been corrected.

The original article can be found online at https://doi.org/10.1007/ s00267-017-0964-7.

Pham Thai Giang

phamthai@frov.jcu.cz

1 Faculty of Fisheries and Protection of Waters, South Bohemian Research Centre of Aquaculture and Biodiversity of

Hydrocenoses, University of South Bohemia in Ceske Budejovice, Zatisi 728/II, 38925 Vodnany, Czech Republic

2 Vetsuisse Faculty, Centre for Fish and Wildlife Health, Department of Infectious Diseases and Pathobiology, University of Bern, Laenggassstrasse 122, Bern 3001, Switzerland

3 Department of Food Science, Aarhus University, P.O. Box 50, DK-8830 Tjele, Denmark 